3

4

5

6

7

\title{
Developmental patterns of a large set of barley (Hordeum vulgare L.) cultivars in response to ambient temperature
}

\author{
I. Karsai ${ }^{1}$, E. Igartua ${ }^{2}$, A.M. Casas $^{2}$, T. Kiss ${ }^{1}$, V. Soós ${ }^{1}$, K. Balla ${ }^{1}$, Z. Bedö ${ }^{1}$ \& O. Veisz \\ 1 Centre for Agricultural Research, Hungarian Academy of Sciences, H-2462 Martonvásár, Hungary \\ 2 Department of Genetics and Plant Production, Aula Dei Experimental Station, EEAD-CSIC, Avda. Montañana 1005, E-50059 Zaragoza, Spain
}

Keywords

Ambient temperature sensitivity; barley; phenophases.

\section{Correspondence}

I. Karsai, Centre for Agricultural Research,

Hungarian Academy of Sciences, H-2462

Martonvásár, Hungary.

Email: karsai.ildiko@agrar.mta.hu

Received: 2 August 2012; revised version accepted: 4 February 2013.

doi:10.1111/aab.12023

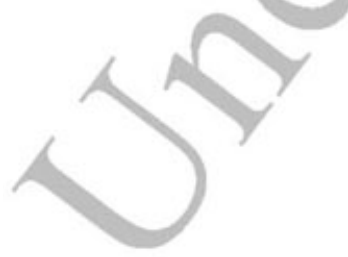

\section{Introduction}

Flowering time is one of the most important factors in the adaptation of plants to their environment. The genetic regulation of physiological processes ensures that flowering occurs under optimal environmental conditions, which thus improves seed set. Plant development and time to flowering are determined primarily by

\begin{abstract}
Ambient temperature plays an important role in plant development. In cereals, little is known about the exact effects of ambient temperature in the range between it being a vernalising agent and an abiotic stress factor; thus the genetic determinants involved in the registering and response to ambient temperature, and their natural variation has not been dissected either. Principally, we wished to establish the level of natural variation in response to ambient temperature in barley via studying plant phenological development. The responses to temperature of 168 barley genotypes of different provenances and seasonal growth habit groups were observed in controlled environments. The effects of four temperature regimes $\left(13^{\circ} \mathrm{C}, 16.5^{\circ} \mathrm{C}, 18^{\circ} \mathrm{C}\right.$ and $\left.23^{\circ} \mathrm{C}\right)$ on the duration of plant phenophases were examined. The plant development was characterised in a series of consecutive phenophases that span the plant life cycle from germination through flowering to attainment of maximum plant height. Ambient temperature affected significantly plant development, with substantial variation in responses among the genotypes. Six major types of responses were identified, which depended strongly on seasonal growth habit, with only a small degree of overlap. Although the differences in the timing of development among clusters were significant under each temperature regime, the $23^{\circ} \mathrm{C}$ treatment resulted in the largest diversity of responses, with significant changes in the ranking of the six clusters compared to other treatments. Two clusters showed particularly unusual responses to 23C: the development of one winter barley cluster was extremely accelerated by the $23 \mathrm{C}$ treatment, whereas the development of one spring barley cluster was significantly delayed. Ambient temperature assumes importance as a regulatory cue in the intricate and complex temporal and spatial regulation network of plant development in cereals and acts mostly through its regulatory effect on certain developmental phases such as the onset and duration of the intensive stem elongation.
\end{abstract} exposure to low temperature, is necessary for the induction of generative development in several temperate plant 
species. The genetic basis of this process has already been described in detail in Arabidopsis and in cereals (Amasino, 2005; Cockram et al., 2007; Trevaskis et al., 2007; Distelfeld et al., 2009). However, much less is known about the effects of temperatures that are above the vernalisation threshold on plant development and gene action.

Temperature is an important seasonal cue and is more complex than photoperiod in relation to both its characteristics and its effects. Photoperiod follows a predictable pattern from year to year, whereas the temperature profile of a given area can show tremendous variation among seasons and years. In addition, temperature affects plant development not only via the daily average temperatures, but also via the amplitude of the daily fluctuations (Yin et al., 1996; Thingnaes et al., 2003; Heggie \& Halliday, 2005; Lobell \& Ortiz-Monasterio, 2007). Most plants in temperate regions face sub- or supra-optimal temperatures on a daily basis and, consequently, need to be able to register and integrate these signals to regulate their development in order to respond to and prevent the adverse effects of environmental changes. Temperature can elicit both developmental and physiological changes that range from subtle metabolic readjustments to dramatic effects on growth and reproduction (Ruelland \& Zachowski, 2010). The genetic factors that are involved in the registration of temperature have been characterised in Arabidopsis. These studies have revealed the presence of an intricate regulatory system with complex crosstalk among the distinct signalling pathways that are regulated by light, plant hormones and temperature, which is in accordance with the complexity of temperature as an environmental cue (Heggie \& Halliday, 2005; Samach \& Wigge, 2005; Balasubramanian et al., 2006; Lee et al., 2008; Penfield, 2008; Franklin, 2009; McClung \& Davis, 2010). These researchers hypothesized the existence of a thermosensory pathway, which acts mostly independently of both the low-temperature vernalisation and photoperiod pathways (Lempe et al., 2005; Balasubramanian et al., 2006; Lee et al., 2007; Franklin, 2009). In addition, new discoveries are constantly being made regarding the roles of other components that are involved in the plant response or downstream signalling to the ambient temperature perception, such as photoreceptors (Halliday et al., 2003), various components of the circadian clock (Farré et al., 2005; Strasser et al., 2009; Salomé et al., 2010; Thines \& Harmon, 2010), various individual genes from lower hierarchical levels of regulatory gene cascades (Halliday et al., 2003; Balasubramanian et al., 2006; Lee et al., 2007; Strasser et al., 2009) and some translational elements (Lee et al., 2010).

In Arabidopsis, the level of natural variation in responses to ambient temperature has been determined in a large set of wild accessions (Lempe et al., 2005). Although the magnitude of responses to ambient temperature is smaller than that of responses to vernalisation and photoperiod, genotypes have been identified which reacted with hastened or delayed plant development to the higher ambient temperature.

In cereals, studies on the effect of ambient temperature on the duration of plant phenophases (Pirasteh \& Welsh, 1980; Slafer \& Rawson, 1995a-c; Atkinson \& Porter, 1996) have been used widely for crop modelling. The various cereal-climate models predict plant development and yield capability, and place a special emphasis on the establishment of the cardinal temperature values, such as the minimal base, maximal base $\left(T_{\text {base }}\right)$ and the optimal temperature $\left(T_{\text {opt }}\right)$ levels, for plant development and organ growth (Atkinson \& Porter, 1996; Porter \& Gawith, 1999; Lobell \& Ortiz-Monasterio, 2007). By necessity, these studies focused on a limited number of cultivars. Although the response to temperature differs significantly among genotypes (Pirasteh \& Welsh, 1980; Slafer \& Rawson, 1995a-c; Porter \& Gawith, 1999), these experiments were not devised as detailed genetic studies. Thus, with very few exceptions, little is known about the genetic determinants of the registration of ambient temperature in cereals (Bullrich et al., 2002; Appendino \& Slafer, 2003; Lewis et al., 2008; Hemming et al., 2012). The importance of investigating the role of ambient temperature (for temperatures greater than the vernalisation threshold) on plant development and flowering in cereals is based on the following facts: (a) the exact nature of the involvement of ambient temperature in the genetic regulatory network for flowering is not understood completely in Arabidopsis and even so less in cereals; (b) limited information is available on the extent and types of responses of cereal cultivars to ambient temperature, as manifested in their plant developmental patterns; (c) the risk of occurrence of extreme or abnormal temperatures during any period of the growing season is increasing because of global climate change, and the effect of this on plant development and flowering needs to be investigated and (d) characterisation of the functional variation in the genes that participate in the registration of temperature might enable flowering to be manipulated without affecting major developmental requirements, such as responses to vernalisation and the photoperiod.

With these facts in mind, our main aim was to establish the extent and types of responses to ambient temperature in a large set of barley cultivars of different provenances that were representative of the three barley seasonal growth habits. Herein, the effect of ambient temperature on barley plant development, particularly on the onset and duration of phenophases are discussed, against a backdrop of diverse barley germplasm. 


\section{Materials and methods}

\section{Plant materials}

A total of 168 barley cultivars of diverse geographical origins (78 from Europe [EU], 78 from North America [NAM], four from Central America [CAM], four from West Asia [WA], two from East Asia [EA] and two from Australia [AUS]) were included in the study. This set of cultivars included representatives of the three barley 10 growth habits (93 spring, 62 winter and 13 facultative) 11 and the two head types (92 two- and 76 six-rowed). 12 Details of the cultivars are listed in Table S1.

\section{Phenotypic characterisations}

\section{Response to ambient temperature}

The experiments were carried out in the Phytotron facilities of the Agricultural Research Institute, Hungarian Academy of Sciences, Martonvásár, using CONVIRON growth chambers (Controlled Environments, Winnipeg, Canada). A combination of standard procedures and standard environmental factors (listed below), excluding temperature, was applied throughout the experiments to facilitate the analysis of ambient temperature alone on plant growth. Germination was carried out in Jiffy pots. After the seedlings had emerged (defined as the emergence of approximately one-third of the first leaf), the plantlets were transferred to the vernalisation chamber. All plants were vernalised for 45 days at $3^{\circ} \mathrm{C}$ under a short photoperiod and a low-light-intensity regime $\left(8 \mathrm{~h}, 12-13 \mu \mathrm{mol} \mathrm{m}^{-2} \mathrm{~s}^{-1}\right.$ photosynthetic photon flux density [PPFD]). After vernalisation, the plantlets (in which the first leaf was fully expanded or the second leaf was just visible) were transplanted into individual pots and placed in the controlled growth chambers. All treatments were subjected to a long photoperiod ( $16 \mathrm{~h}$ light/8 h dark) and light intensity of $200-240 \mu \mathrm{mol} \mathrm{m}^{-2} \mathrm{~s}^{-1}$ PPFD, which was provided by metal halide lamps. Four ambient temperature treatments were applied in four separate growth chambers: (a) $13^{\circ} \mathrm{C}$ constant temperature (referred to as $13 \mathrm{C}$ ), (b) $18^{\circ} \mathrm{C}$ daytime $/ 15^{\circ} \mathrm{C}$ night temperature with a daily average of $16.5^{\circ} \mathrm{C}(16.5 \mathrm{C}),(\mathrm{c}) 18^{\circ} \mathrm{C}$ constant temperature (referred to as $18 \mathrm{C}$ ) and (d) $23^{\circ} \mathrm{C}$ constant temperature (referred to as 23C). Each treatment was applied in one growth chamber. Given that the number of plants that can be allocated to a chamber is fixed the design of the experiment in terms of number of treatments and number of genotypes was a trade-off between the total number of plants that could be handled, the minimum number of replicates that would ensure reliable results and maximum coverage of barley germplasm. Thus each genotype was replicated twice per treatment (two pots per genotype; with a soil capacity of approximately $1.5 \mathrm{~kg} \quad 1$ of each pot, giving a density of 60 plant $\mathrm{m}^{-2}$ ). 2

The following parameters were recorded for all plants 3 twice per week: number of leaves on the main stem, 4 height from the soil surface of the last leaf sheath on the main stem and number of side tillers. In addition, the plants were checked regularly for the appearance of the first node at the base of the main stem (plant developmental phase 31 or DEV31; Tottman \& Makepeace, 1979), and for the appearance of the awns just visible above the last leaf sheath (DEV49). The plants were grown to full maturity, upon which six yield components were determined for each plant: number of reproductive tillers, number of seeds, 1000-kernel weight on the main stem, average number of seeds and 1000-kernel weight on the side tillers and total seed yield per plant.

The associations between the thermal time and time course data for plant height, number of tillers and number of leaves were calculated. Thermal time was expressed as growing degree days (GDD) with the equation:

$$
\mathrm{GDD}=\Sigma\left(\left(T_{\max }+T_{\min }\right) / 2\right)-T_{\text {base }}
$$

where $T_{\text {base }}$ was set to $0^{\circ} \mathrm{C}$. This calculation was performed in accordance with the method of McMaster (2005), using the mean values for the two plants per genotype, at each time point.

The regular monitoring of the plant developmental parameters made it possible to identify a series of consecutive phenophases that spanned the life cycle from germination to attainment of maximum plant height, and some critical physiological milestones of plant development (the method was described by Kiss et al., 2011). The associations between thermal time and time-course data were characterised by linear regressions in the case of leaf number and determination of the tillering period, whereas changes in plant height followed a sigmoid curve with three distinct stages that fitted with linear regressions. Thus, the linear regression equations were used to calculate the duration of the phenophases and several plant developmental parameters. These regressions were calculated using the averages of leaf number, and plant height for the two plants per genotype and treatment, as the best estimate for each data point. The onset of the intensive stem elongation phase (DEV30) was considered to be the point of intersection between the first two linear components of the regression of plant height versus time $\left(y_{\text {initial growth }}\right.$

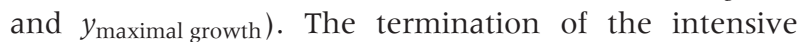
stem elongation phase (DEV_SEend) was the point of intersection between $y_{\text {maximal growth }}$ and $y_{\text {end growth }}$. The phenophases were defined as follows: the beginning (DEV21) and end (DEV29) of tillering, appearance of the first main stem node (DEV31), onset of intensive stem 
elongation (DEV30), appearance of the flag leaf (DEV37), full expansion of the flag leaf (DEV39), heading date (DEV49), end of intensive stem elongation (DEV_SEend) and attainment of maximum plant height (DEV_PHfinal). In addition, the following parameters were used: the phyllochron (the thermal time required for the expansion of each consecutive leaf), partitioning of the final leaf number between the vegetative and generative phases, tiller number at different developmental stages, rate of tillering and the ratio between the maximum number of tillers and number of reproductive tillers.

\section{Determination of the response to vernalisation}

The response to vernalisation of the entire set of barley cultivars was evaluated. A period of vernalisation was imposed using the Martonvásár Phytotron in accordance with procedures described previously (Karsai et al., 2004). Vernalisation was applied in 15-day increments up to a total of five applications from no vernalisation to 60 days of vernalisation, at a temperature of $3^{\circ} \mathrm{C}$ under an $8 \mathrm{~h}$ light/16h dark photoperiod and low light intensity $\left(12-13 \mu \mathrm{mol} \mathrm{m}{ }^{-2} \mathrm{~s}^{-1}\right.$ PPFD). After vernalisation, seedlings from all treatments were transplanted by hand into the field at Martonvásár, Hungary, on 25 March 2010, when the average photoperiod was longer than $12 \mathrm{~h}$ and increasing. The characteristics of two plants were recordéd per genotype and treatment. For each plant, the number of days to flowering (DEV49) was scored. The trial was terminated after 100 days. For statistical analyses, plants that reached the generative phase but did not head were assigned a value of 120 days to heading, whereas for plants that remained in the vegetative phase this value was set to 150 days.

\section{Characterisation of genotype}

The barley genotypes were analysed with gene-specific primers for the major genes for the response to vernalisation (VRN-H1, VRN-H2 and VRN-H3) and sensitivity to photoperiod (PPD-H1 and PPD-H2) to determine their types with respect to seasonal growth habit and sensitivity to photoperiod. In the case of $V R N-H 1$, the structure of intron 1 was examined with the diagnostic marker sets suggested by von Zitzewitz et al. (2005) and Szúcs et al. (2007). In the set of barley germplasm investigated, 10 different alleles were detected for intron 1 (see Table 2 ). The characteristics of all but one of these alleles have been published previously (Cockram et al., 2007; Hemming et al., 2009); the exception was the allele designated 1190 in Table 2, which was found to be characteristic of certain Spanish barley cultivars (Orria and GenBank accession no. DQ492705; unpublished data). Of the 10 alleles, four alleles [HvVRN1-4, HvVRN1-6, and the two wild-type alleles vrnHl(5200) and vrnHl(5300)] are considered to be recessive winter alleles (Hemming et al., 2009; Casao et al., 2011), while the others are dominant spring alleles. For the other four genes, diagnostic primer pairs were used. In the case of $V R N-H 2$, the primer pair identified the presence/absence (dominant winter/recessive spring) of the $V R N-H 2 a$ and $V R N-H 2 b$ genes (Karsai et al., 2005). For $V R N-H 3$, the genotypes were determined on the basis of two single nucleotide polymorphisms (SNPs) in intron 1, as reported by Yan et al. (2006). In the case of PPD-H1, a cleaved amplified polymorphic sequence marker identified the diagnostic SNP 22 in exon 7 (Turner et al., 2005), for which the longer fragment size (506 bp) was characteristic of the insensitive (recessive) allele, whereas the shorter fragment size ( $432 \mathrm{bp}$ ) corresponded to the sensitive (dominant) allele. In the case of $P P D-H 2$, the primer pair identified the presence of the full gene (dominant, functional allele) or that of the truncated gene (recessive, non-functional allele) (Faure et al., 2007). Barley genotypes with a winter growth habit carried one of the $V R N-H 1$ winter alleles together with the presence of the ZCCT-H genes diagnostic for the winter allele at the $V R N-H 2$ locus. Genotypes with a spring growth habit were characterized by spring alleles at the $V R N-H 1$ locus, irrespective of the presence or absence of $V R N-H 2$. Cultivars that carried the same $V R N-H I$ allele as the winter genotypes (with the exception of HVVRN1-4) but lacked $V R N-H 2$ were considered to be facultative genotypes.

\section{Statistical analyses}

The data were processed using Microsoft Excel and Statistica 6 for Windows software. A two-way ANOVA for all traits measured directly was performed, considering genotypes and temperature treatments as fixed factors. The replicate factor was nested within temperature treatments, therefore making the design a split-plot, with temperature treatments as main plots and genotypes as sub-plots. The variables that were measured or recorded at each plant (listed above) were analysed after the splitplot design, with LSDs calculated separately for each of the factors of the analysis. The variables derived by regression could not be analysed in the same way, as there were no replicates. In this case, we used the interaction genotype-by-temperature as error, assuming that it is an overestimation of the error (as it includes the true experimental error plus the genotype by temperature interaction), but it is useful to describe overall treatment differences. There was a source of experimental error that is confounded with temperature treatment. This is the difference between growth chambers as each temperature 

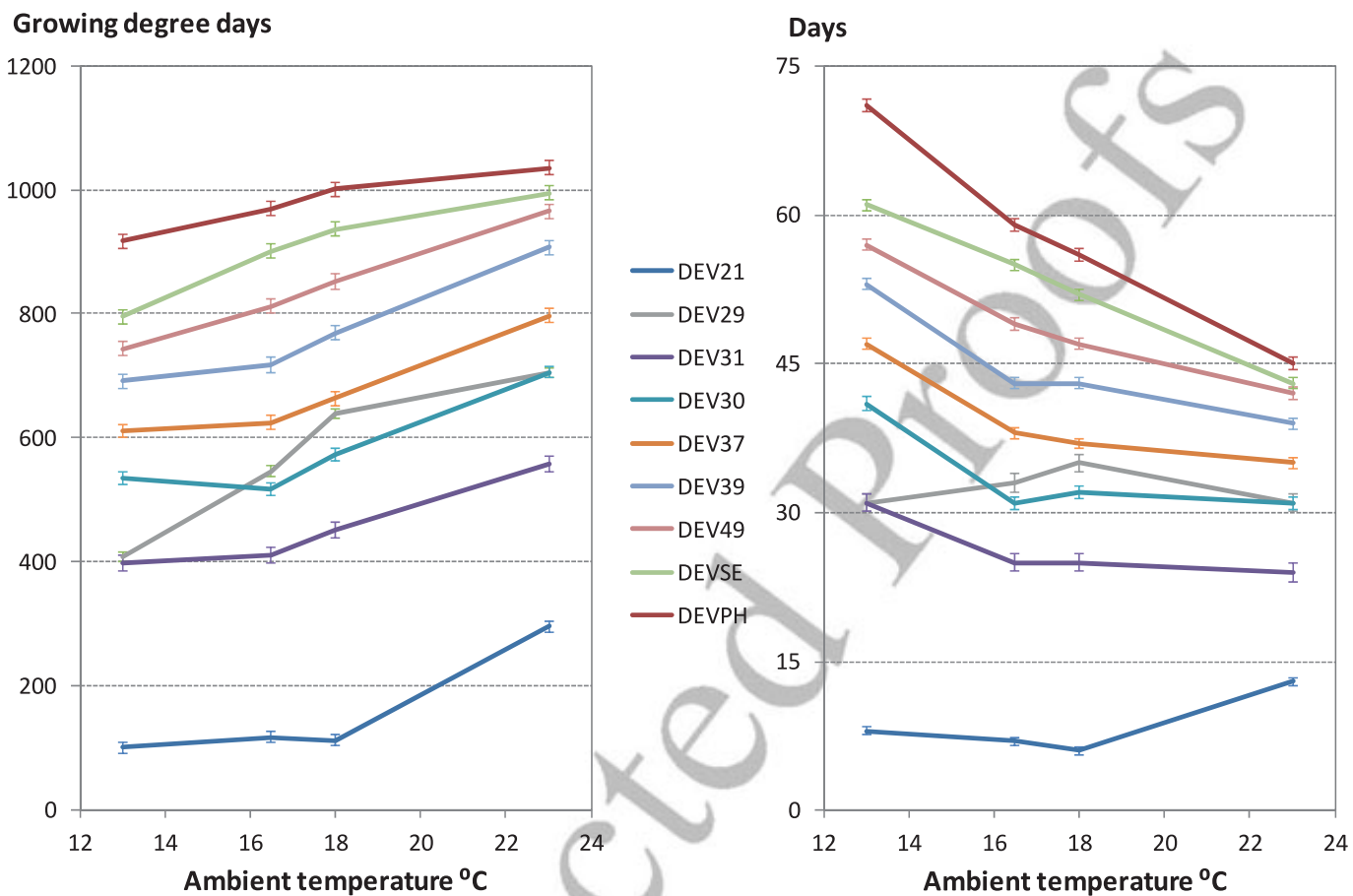

Figure 1 Change in the thermal time (GDD) and chronological time (days) required to reach a given developmental phase at different ambient temperatures averaged over 168 barley cultivars (with error bars representing the significant differences).

treatment occupied one chamber. Therefore, any possible difference between chambers is actually accounted for by the temperature treatments. These differences, in any case, was not of a magnitude large enough to override the true effect of the treatments, because the trends of plant growth between temperatures were smooth and steady, as seen in Fig. 1.

Cluster analysis was carried out by applying the UPGMA method to the squared Euclidean distance matrix that was derived from the phenotypic data sets consisting of the GDD values of the plant developmental phases measured under the four temperature treatments. The groupings obtained were verified and analysed further using the $k$-means clustering, general discriminant analysis (GDA) and principal component analysis (PCA) functions of the Statistica 6 software package. The probable number of independent clusters was accepted based on the results of $k$-means clustering and GDA.

\section{Results}

The results of the growth chamber experiment can be expressed in days or GDD. The choice of unit is not trivial because the relationship between chronological time (days) and thermal time (GDD) is not constant. At higher temperatures, thermal time accumulates faster than chronological time. Consequently, the graph of the reaction of phasal development against temperature assumed different shapes depending on which variable was chosen (Fig. 1). The total thermal time required to complete the growth cycle increased by $13 \%$ at 23C averaged over the 168 barley genotypes, compared to that at $13 \mathrm{C}$, whereas the same comparison for chronological time showed a reduction of $37 \%$. However, for comparative purposes, these differences do not affect the conclusions regarding the differential responses of groups of barley genotypes to temperature (which will be described below). We favoured the use of thermal time because the physiological and biochemical processes that underlie plant development respond to temperature (Bonhomme, 2000; Trudgill et al., 2005).

In addition to the constant temperature, the daily fluctuating temperature treatment was also applied for characterising its effect on plant development. Under the given set of experimental factors, however the effect of the thermocycle of 18/15C was not significantly different in its tendencies from that of the constant temperature of 18C, averaged over the genotypes (Table 1). The largest source of the difference found between the results of the barley cultivars here and those published by Karsai et al. (2008) lies mostly in the different source of lights (metal halide lamps versus fluorescent tubes, respectively). Metal halide lamps as light sources are more inductive to plant
(1)

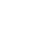

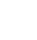

(1)

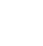


Table 1 Average values for plant morphological traits under four ambient temperature treatments including the LSD values

\begin{tabular}{|c|c|c|c|c|c|}
\hline \multirow[b]{2}{*}{ Trait } & \multicolumn{5}{|c|}{ Temperature treatment } \\
\hline & $13 \mathrm{C}$ & $16.5 \mathrm{C}$ & $18 \mathrm{C}$ & 230 & $\operatorname{LSD}(0.05)$ \\
\hline Duration of stem elongation (GDD) & 292 & 382 & 364 & 289 & 17 \\
\hline Duration of tillering period (GDD) & 307 & 430 & 527 & 408 & 36 \\
\hline Leaf number at DEV31 & 6.2 & 5.9 & 6.0 & 6.1 & 0.1 \\
\hline Leaf number at DEV31 (\%) & 63.4 & 63.4 & 65.0 & 67.3 & 1.1 \\
\hline Phyllochron (GDD) & 79 & 88 & 93 & 115 & 2 \\
\hline Final leaf number ${ }^{a}$ & 9.9 & 9.3 & 9.3 & 9.1 & \\
\hline Plant height at DEV31 (cm) & 12.9 & 12.7 & 12.4 & 11.9 & 0.4 \\
\hline Plant height at DEV49 (cm) & 56.7 & 53.4 & 48.7 & 39.9 & 1.2 \\
\hline Final plant height $(\mathrm{cm})^{\mathrm{b}}$ & 67 & 65 & 58 & 44 & \\
\hline Rate of plant height growth (GDD) & 6 & 8 & 9 & 11 & 1 \\
\hline
\end{tabular}

development than the fluorescent tubes, resulting in much quicker plant development in general (data not shown). Under metal halide lamps the phenological data originated from the thermocycle experiment actually fitted well to the tendencies obtained with the use of constant temperature, thus these data were used in the further analyses as representing an extra temperature point in the equations (Fig. 1).

\section{General effect of ambient temperature on plant development}

Averaged over the 168 barley cultivars, the ambient temperature affected significantly the thermal and chronological time required to reach the different phenophases and other developmental parameters (Fig. 1). As the ambient temperature was increased from $13 \mathrm{C}$ to $23 \mathrm{C}$, the chronological time required to complete each developmental phases decreased, except for the beginning and the end of tillering. For the earlier developmental phases (up to DEV37), this difference was only evident between $13 \mathrm{C}$ and all other temperatures, but for the later phases the values were significantly different between each level of ambient temperature tested. However, the decrease in chronological time was not sufficiently large to offset the increase in daily average temperature. Consequently, the thermal time required to reach a phenophase increased in parallel with ambient temperature (Fig. 1). At 23C, a marked delay in development as early as DEV21 was observed. As plant development progressed, the delay in development that was caused by increased temperature was evident at increasingly lower temperatures: for DEV31 this phenomenon could be observed at 18C, and for DEV49 (and subsequent stages) at 16.5C.
Parallel to the significant increase in phyllochron, a less marked, but still significant, decrease in final leaf number was observed, which mainly affected the portion of leaves that expanded during the generative phase (Table 1). The length of the intensive stem elongation phase (expressed in thermal time) was shortest in the $13 \mathrm{C}$ and $23 \mathrm{C}$ treatments, and longest at $16.5 \mathrm{C}$ and $18 \mathrm{C}$. The rate of increase in plant height (the thermal time required for $1 \mathrm{~cm}$ of stem growth in the intensive growing phase) increased significantly with temperature. As a result of these two tendencies, the plant height at DEV49 and the final plant height were significantly lower at successively higher ambient temperatures.

Ambient temperature-dependent plant developmental patterns

In the two-way ANOVA, genotype had a strong effect on plant development, both as a main factor and in interactions with temperature (Table S2). Consequently, the data matrix of thermal times for the nine developmental phases, 168 cultivars, and four temperature treatments was subjected further to multifactorial analyses. The first five factors in the PCA analysis showed an eigenvalue higher than 1, and collectively explained $87.0 \%$ of the total variance. The first and second factors alone explained $77.7 \%$ of the variance $(70.0 \%$ and $7.7 \%$, respectively). The first factor showed the strongest correlations (between -0.849 and -0.963 ) with the thermal time values of the phenophases (with the exception of DEV21 and DEV29) measured under the 13C, 16.5C and 18C conditions. The second factor was correlated more strongly with the thermal times of the phenophases determined at $23 \mathrm{C}$ (in the range 0.439 to 0.576 ), with the exception
1 2 3 4 5 6 7 8 


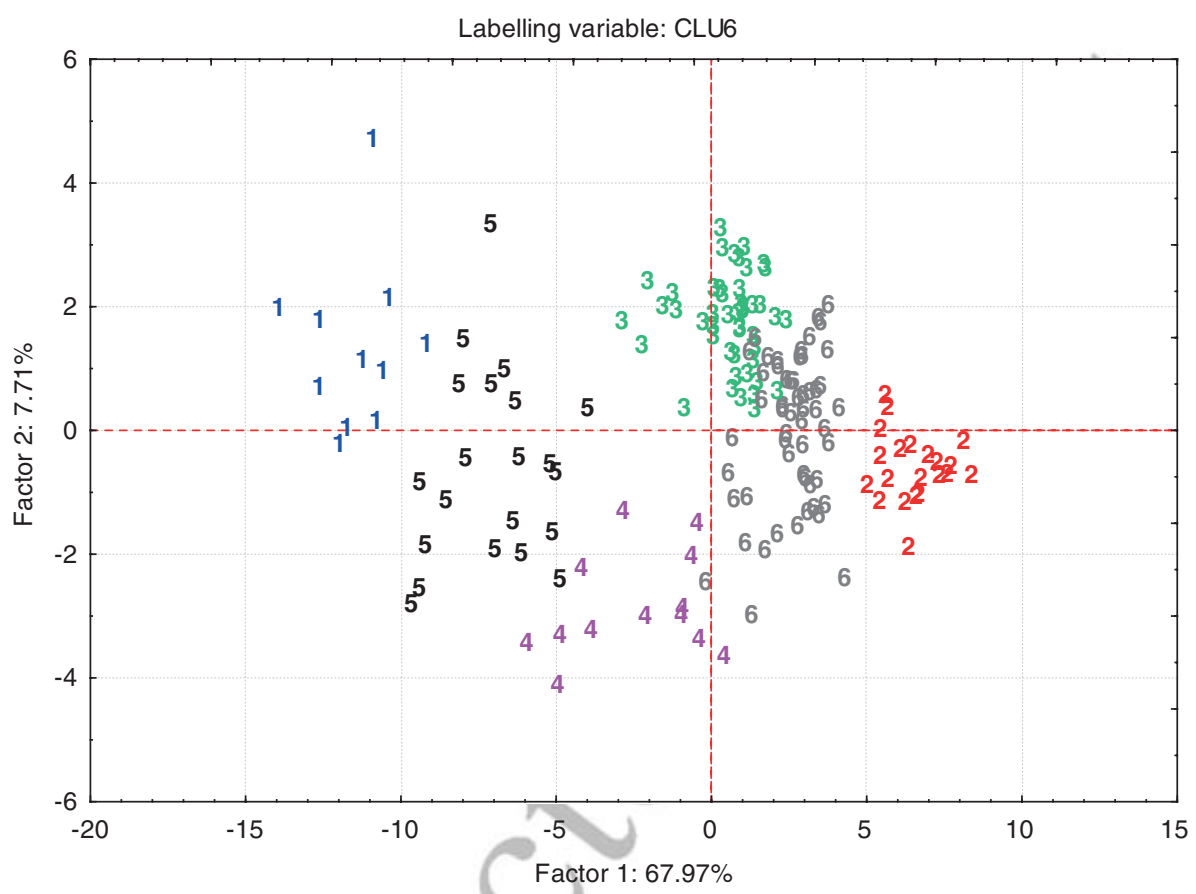

Figure 2 Principal component analysis (PCA) of the 168 barley cultivars based on the values of thermal time required to attain each of nine phases of plant development (DEV21, DEV29, DEV31, DEV30, DEV37, DEV39, DEV49, DEV_SEend and DEV_PHfinal) measured under four ambient temperature regimes (13C, 16.5C, $18 \mathrm{C}$ and $23 \mathrm{C})$.

of DEV21. The beginning of tillering (DEV21) appeared to be correlated with the third factor (data not shown).

The $k$-means cluster analysis offered two possible results based on one of two different criteria. Either four (where $\Delta k$ was the highest) or six [where $\operatorname{diff}(\Delta k)$ was the lowest and negative] separate clusters of cultivars could be distinguished. However, the discriminant analysis supported a higher probability of six clusters: the percentage of correct classifications and the distances between the clusters increased, whereas the average distances within the clusters decreased, when the number of clusters was increased from four to six (Fig. S1).

The six clusters, which represented different plant developmental patterns in response to the ambient temperature, were represented in the first and second factorial axes of the PCA (Fig. 2). These clusters are differentiated by some interesting characteristics regarding geographical origin, ear type, seasonal growth habit and allelic frequencies for the major flowering time genes (Table 2). European cultivars were distributed relatively evenly among the six clusters, whereas the majority of North American cultivars were distributed between two clusters, Clu3 and Clu6. With regard to ear type, the majority of the cultivars in Clul and Clu3 were two-rowed, whereas Clu4 included mostly six-rowed types, and the other clusters included similar numbers of genotypes of each ear type. With regard to seasonal growth habit, Clul, Clu4 and Clu5 consisted solely of winter cultivars, Clu3 and Clu6 comprised the majority of the spring cultivars (together with a few winter genotypes), whereas Clu2 contained most of the facultative cultivars (later on, these clusters will be referred to according to the most frequent types of seasonal growth habit present in each cluster). One of the differences between the three winter barley clusters was the allele frequencies for PPD-H1. Approximately two-thirds of the winter barley cultivars in Clul carried the insensitive allele, whereas two-thirds of the cultivars carried the sensitive allele in Clu5. All cultivars in Clu4 carried the sensitive allele. Of the two spring barley clusters, Clu6 contained a higher proportion of winter genotypes (13 out of 55 cultivars) than Clu3, which resulted in higher frequencies of the winter allele at $V R N-H 2$ and the sensitive allele at PPD-H1.

With the exception of DEV21, significant differences were observed among the average values of thermal time required to reach the different developmental phases for the six clusters at all four ambient temperatures (Table S3). It has been noted above that the ambient temperature affected significantly the thermal time required to reach a given developmental phase, but this effect varied widely among the six clusters (Fig. 3). 
Table 2 Characterisation of the six ambient temperature-dependent clusters of barley cultivars of different growth habits with regard to ear type, growth habit, provenance and allelic composition for the major genes that affect time to flowering (VRN-H1 alleles highlighted in bold are the recessive, winter alleles)

\begin{tabular}{|c|c|c|c|c|c|c|c|}
\hline Character & Type & $\begin{array}{l}\text { Cluster_1 } \\
N=11\end{array}$ & $\begin{array}{l}\text { Cluster_2 } \\
N=21\end{array}$ & $\begin{array}{l}\text { Cluster_3 } \\
N=47\end{array}$ & $\begin{array}{l}\text { Cluster_4 } \\
N=13\end{array}$ & $\begin{array}{l}\text { Cluster_5 } \\
N=21\end{array}$ & $\begin{array}{l}\text { Cluster_6 } \\
N=55\end{array}$ \\
\hline \multirow[t]{2}{*}{ Ear type } & 2 & 8 & 9 & 39 & 2 & 10 & 24 \\
\hline & 6 & 3 & 12 & 8 & 11 & 11 & 31 \\
\hline \multirow[t]{3}{*}{ Growth habit } & Spring & 0 & 8 & 46 & 0 & 0 & 39 \\
\hline & Facultative & 0 & 10 & 0 & 0 & 0 & 3 \\
\hline & Winter & 11 & 3 & 1 & 13 & 21 & 13 \\
\hline \multirow[t]{6}{*}{ Provenance } & AUS & & 2 & & & & \\
\hline & EA & & 2 & & & & \\
\hline & WA & 1 & 1 & & & 1 & 2 \\
\hline & NAM & 1 & 5 & 34 & 4 & 3 & 31 \\
\hline & CAM & & & & & & 2 \\
\hline & EU & 9 & 11 & 12 & 9 & 17 & 20 \\
\hline \multirow[t]{10}{*}{$V R N-H 1$ intron $1^{a}$} & VRN1-1 & & 3 & 28 & & & 20 \\
\hline & VRN1-2 & & & 2 & & & 7 \\
\hline & VRN1-3 & & & 10 & & & 7 \\
\hline & 1190 & & & & & & 1 \\
\hline & VRN1-4 & & & 4 & & & 3 \\
\hline & VRN1-5 & & 1 & 1 & & & 3 \\
\hline & VRN1-6 & & & & 2 & & 1 \\
\hline & VRN1-7 & & & 1 & & & \\
\hline & vrnH1(5200) & & 5 & 1 & 6 & 12 & 4 \\
\hline & vnrH1(5300) & & 5 & & 5 & 9 & 9 \\
\hline \multirow[t]{2}{*}{ VRN-H2 gene } & Spring (absent) & 0 & 16 & 44 & 0 & 0 & 34 \\
\hline & Winter (present) & 11 & 5 & 3 & 13 & 21 & 21 \\
\hline \multirow[t]{2}{*}{ VRN-H3 intron 1 SNP } & $A G$ & 3 & 2 & 15 & 5 & 2 & 18 \\
\hline & $\mathrm{TC}$ & 8 & 19 & 32 & 7 & 19 & 37 \\
\hline \multirow[t]{2}{*}{ PPD-H1 22. SNP } & Recessive & 8 & 2 & 46 & 0 & 6 & 41 \\
\hline & Dominant & 3 & 19 & 1 & 13 & 15 & 14 \\
\hline \multirow{2}{*}{ PPD-H2 gene } & Recessive (truncated) & 9 & 11 & 2 & 11 & 16 & 9 \\
\hline & Dominant (full) & 2 & 10 & 45 & 2 & 5 & 46 \\
\hline
\end{tabular}

${ }^{a}$ Classification is based on Hemming et al. (2009).

${ }^{\mathrm{b}}$ Classification is based on Turner et al. (2005).

The ambient temperature had the smallest effect on the development of cultivars in Clu2, which contained the majority of the facultative cultivars. This group almost always reached a given developmental phase first at each ambient temperature, the only exception being the thermal time needed to reach DEV21 at 23C (Fig. 4). The differences between the two clusters that contained the majority of spring cultivars (Clu3 and Clu6) were relatively small at 13C. However, at higher temperatures, the differences between these two groups for the phenophases between DEV31 and DEV49 increased significantly and were most pronounced at 23C. For all developmental phases, Clu6 required a shorter thermal time than Clu3. In the case of the three winter barley clusters, the thermal time required for each consecutive phase tended to increase significantly between the ambient temperature regimes of $13 \mathrm{C}$ and 18C, and this increase more or less paralleled the increase in ambient temperature. Clul cultivars always presented the slowest development and cultivars in Clu4 the fastest, in a statistically significant manner, whereas Clu5 had intermediate values and differed significantly from Clul and Clu4 for most variables (Fig. 3, Table S3). Just as in the case of the spring cultivars, the $23 \mathrm{C}$ treatment resulted in the largest differences among the responses of the three winter barley clusters. For the cluster that developed the slowest in general (Clul), the $23 \mathrm{C}$ treatment resulted in a further increase in the thermal time required to reach each developmental phase. For Clu5, the increase in thermal time at 23C was only significant for the DEV31 phase; for the later phases no significant differences between the values measured at $18 \mathrm{C}$ and $23 \mathrm{C}$ were observed. The most striking characteristic at 23C was shown by the genotypes in Clu4, which showed a large decrease in the thermal time required to reach each phase; in fact, the values were the same as those obtained with the 13C treatment. As a result, Clu4 was the second earliest cluster at 23C at DEV49. 


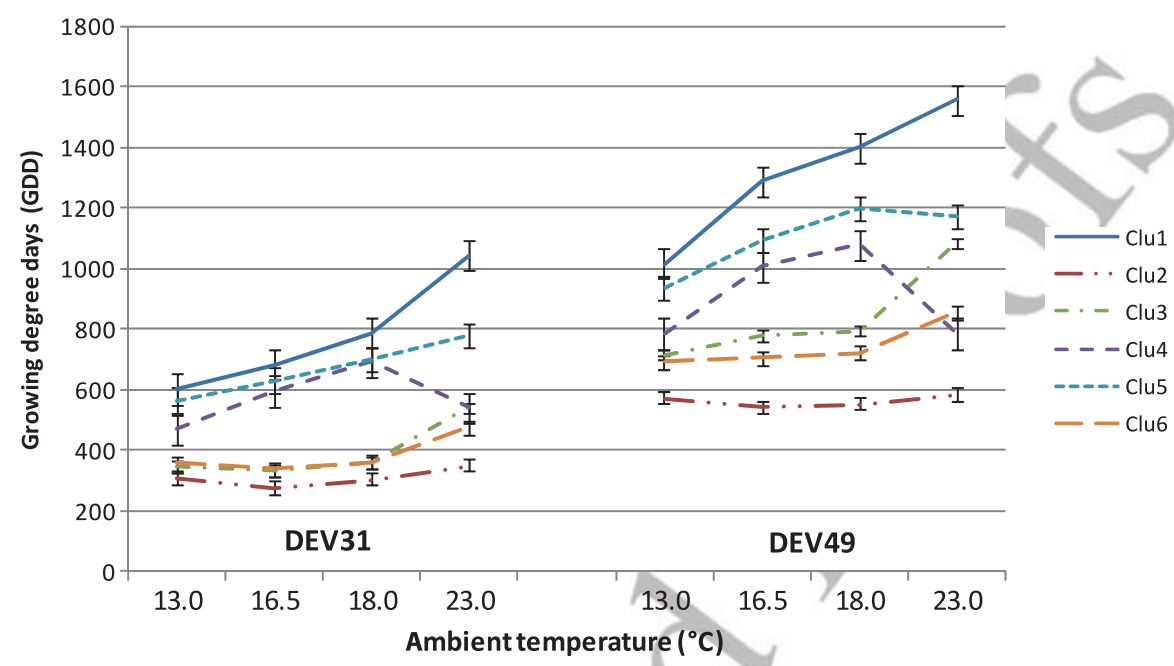

Figure 3 Thermal times required to attain the plant developmental phases of DEV31 (appearance of the first main stem node) and DEV49 (awn just visible) in the six clusters of barley cultivars with different growth habits under four ambient temperature treatments.

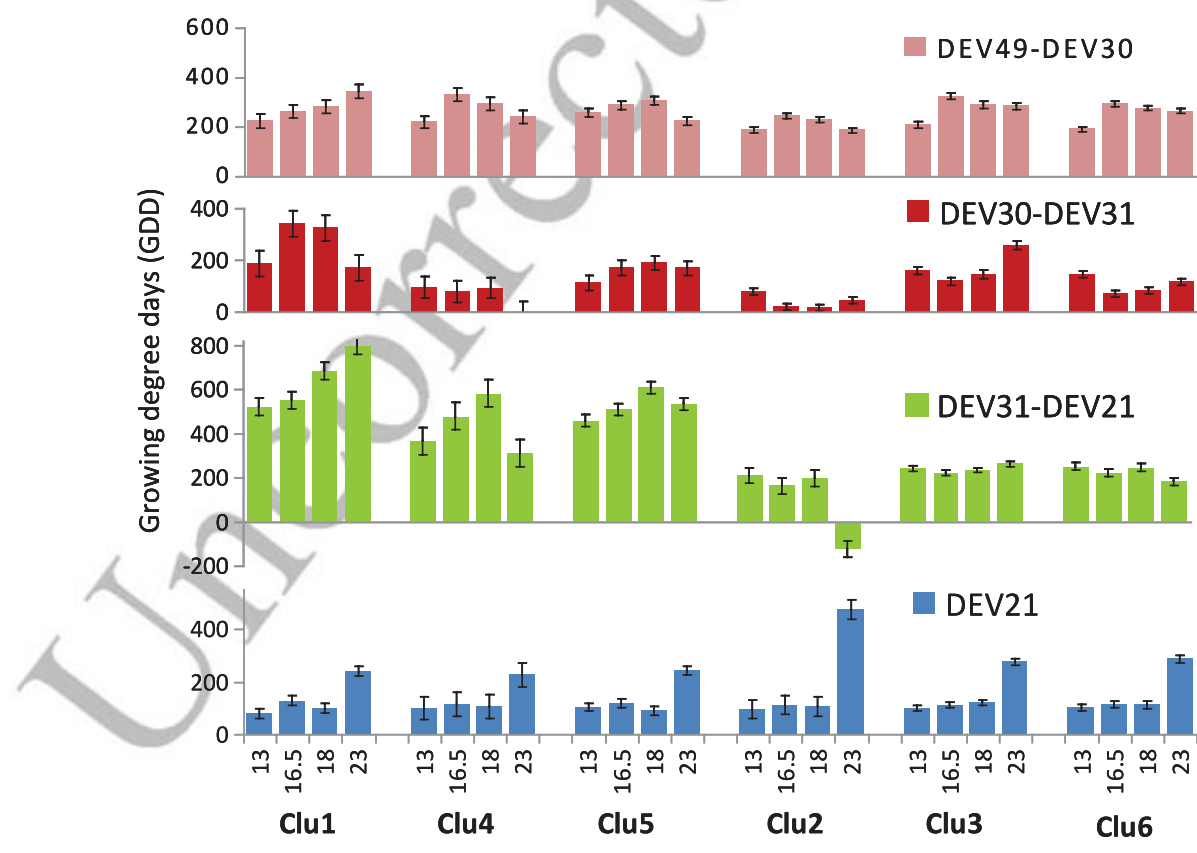

Figure 4 Differences in thermal time between two consecutive developmental phases in the six clusters of barley cultivars with different developmental patterns, under four ambient temperature regimes. The clusters are ordered as winter-facultative-spring: Clu1, Clu4, Clu5, Clu2, Clu3 and Clu6.

The duration of the period between two consecutive phenophases was also analysed (Fig. 4). In general, the thermal time needed to complete DEV21 was increased clearly at 23C, in all clusters. However, Clu2 showed the largest delay. The phase between DEV21 and DEV31 showed marked differences in response to temperature among the winter clusters. For Clul, the thermal time of this phase increased continuously with increasing temperature, whereas for Clu4 and Clu 5 the thermal time peaked at $18 \mathrm{C}$ and then decreased to different extents at 23C. Clu2 showed a shortening of this phase at $23 \mathrm{C}$, in a manner similar to that of Clu4. The period between DEV31 (appearance of the first main stem node) and DEV30 (the beginning of intensive stem elongation) proved to be a critical phase in determining the rate of plant development. In these controlled environmental tests, the appearance of the first main stem node usually occurred earlier than the onset of 
intensive stem elongation, but the extent of the difference depended on both the ambient temperature and the genotype. Significant positive correlations $(r=0.45$ to 0.68 ) between the length of the DEV $30-D E V 31$ phase and the thermal time of the later developmental phases were observed under three of the four ambient temperatures (the exception was 13C). In general, the DEV30-DEV31 period was shortest in Clu2 (the fastest developing group) and longest in Clul (the slowest developing group). The shape of the temperature-dependent response for the DEV30-DEV31 phase was similar for the facultative and the two spring barley clusters (Clu3 and Clu6). In these clusters, the period was longest at $13 \mathrm{C}$ and showed a significant decrease at higher temperatures; it was similar for Clu2 and Clu6 in the range $16.5 \mathrm{C}$ to $23 \mathrm{C}$, whereas Clu3 showed a sharp increase in thermal time at 23C. The two spring cultivar clusters showed similar thermal times for most of the other phases. However, between DEV31 and DEV30, they showed different absolute thermal durations that increased as the temperature increased, with a maximum at $23 \mathrm{C}$. With regard to the three winter barley clusters, the duration of this period increased (in Clul) or was relatively similar (in Clu4 and Clu5) between 13C and 18C, and then decreased at 23C. These temperature-dependent changes in the duration of the DEV30-DEV31 interval were largest in Clul.

Association between yield components and ambient temperature

The ambient temperature had a strong effect on seed yield and yield components. Averaged over the 168 barley cultivars, all yield components, and thus the final seed yield per plant, were highest at $13 \mathrm{C}$ and decreased significantly at successively higher ambient temperatures (Table 3). This decrease was smallest for 1000-kernel weight measured for both the main ear and side tillers. The seed number and seed weight of the main tiller and the number of reproductive side tillers decreased to a greater extent at the higher temperatures than at the lower temperatures. However, the major contributor to the decreased yield was the marked decrease in fertility of the side tillers. These trends were similar for all six of the growth habit clusters, although the overall rate of decline depended on the time required for the cultivars within a given cluster to reach each developmental stage (Table S4). The decrease in yield and fertility was most marked in Clul, in which the rate of plant development at $23 \mathrm{C}$ was delayed to the greatest extent, whereas the reduction in yield components in clusters that developed earlier (the spring and facultative clusters and Clu4 of the winter cultivars) was significantly less severe.

Responses to vernalisation respenses of the barley cultivar clusters

The responses to vernalisation of the cultivars were monitored in a separate experiment, in which the plants were vernalised artificially for five different periods, then transplanted simultaneously to the field in spring (when the photoperiod was longer than $12 \mathrm{~h}$ and increasing). The number of days to reach heading (DEV49) was recorded. Vernalisation had a significant effect on the time needed to reach DEV49 for all six clusters (Fig. 5). The effect was greatest for the three winter barley clusters (Clul, Clu4 and Clu5) and smallest for the facultative and spring barley clusters (Clu2, Clu3 and Clu6). The vernalisation requirements of Clu2, Clu3, Clu4 and Clu6 were apparently saturated by 30 days of artificial vernalisation because the number of days required to reach DEV49 did not decrease in response to a longer vernalisation period, whereas 45 days of vernalisation was the saturation threshold for the other two clusters. The trends in the curves for the responses to vernalisation for the six clusters were similar to those obtained for the responses to the ambient temperature treatments. Clu2 (facultative cultivars) was always the earliest, whereas Clul was always the last, to achieve heading. Of the two spring barley clusters, Clu6 (which included some winter cultivars) developed significantly earlier than Clu3

Table 3 Changes in yield components under the four ambient temperature treatments averaged over all 168 barley cultivars, with the LSD values between temperatures (LSD-T), genotypes (LSD-G) and any two values (LSD-TXG)

\begin{tabular}{|c|c|c|c|c|c|c|c|}
\hline Trait & $13 C$ & $16.5 \mathrm{C}$ & $18 \mathrm{C}$ & $23 C$ & LSD-T & LSD-G & LSD-TxG \\
\hline No. of reproductive tillers & 4.3 & 3.5 & 2.9 & 2.0 & 0.2 & 0.6 & 1.3 \\
\hline Seed no. in the main ear & 44.7 & 36.8 & 33.5 & 20.2 & 0.7 & 3.4 & 6.8 \\
\hline Seed weight in the main ear (g) & 2.4 & 1.7 & 1.5 & 0.8 & 0.1 & 0.2 & 0.4 \\
\hline 1000-Kernel weight in the main ear (g) & 55.4 & 49.9 & 46.2 & 38.3 & 1.4 & 2.7 & 5.5 \\
\hline Seed no. in the side tillers & 128.8 & 90.7 & 62.2 & 23.4 & 8.3 & 17.6 & 35.5 \\
\hline Seed weight in the side tillers (g) & 6.0 & 3.5 & 2.3 & 0.8 & 0.4 & 0.8 & 1.5 \\
\hline 1000-Kernel weight in the side tillers (g) & 48.6 & 39.4 & 36.0 & 28.4 & 6.7 & 1.9 & 13.4 \\
\hline Seed yield per plant (g) & 8.4 & 5.3 & 3.8 & 1.6 & 0.4 & 0.8 & 1.6 \\
\hline
\end{tabular}




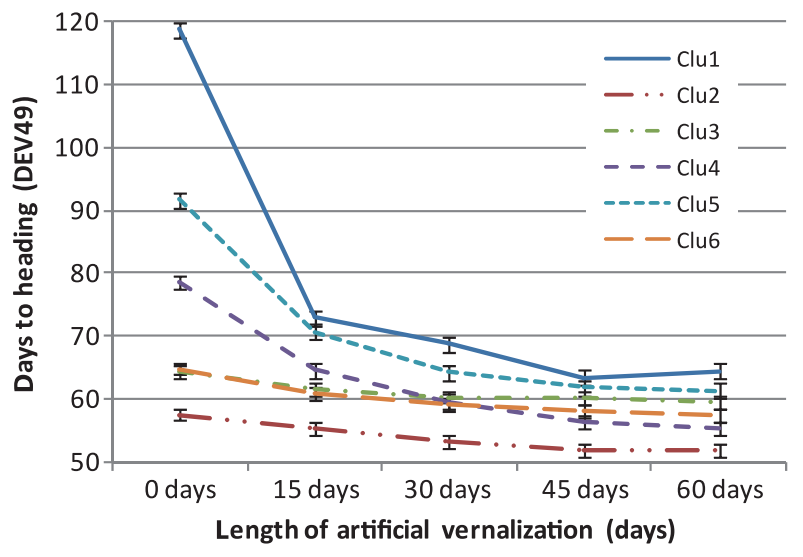

Figure 5 Average responses to vernalisation of six barley clusters with different developmental patterns determined under field conditions following artificial vernalisation treatments for 0-60 days.

after the saturation threshold for vernalisation had been reached. The DEV49 values of two of the winter barley clusters (Clul and Clu5) did not differ significantly after 15 days of vernalisation, even though their saturation thresholds were 45 and 30 days, respectively. In contrast, in Clu4, DEV49 occurred gradually earlier with increasing duration of vernalisation to such an extent that, at the saturation point, heading occurred significantly earlier than in the late-developing spring barley cluster Clu3.

To check the accuracy of the observed similarity between the responses to ambient temperature and vernalisation that were identified for the six clusters, we calculated correlations between the DEV49 values (the thermal and chronological times yielded similar correlation values) of the 168 genotypes at the four ambient temperatures in growth chambers and the chronological data for DEV49 in the field after the five vernalisation treatments. For the complete set of cultivars, all possible correlations were positive and highly significant ( $r=0.44$ to 0.76 ) (Table S5). However, when correlations were analysed within each of the three subgroups (in the facultative cluster, in the two spring cultivar clusters, and in the three clusters of winter cultivars) significant differences were apparent. For the spring cultivars, the correlation between DEV49 at 13C and DEV49 after 45 days vernalisation was the strongest $\left(r=0.49^{\text {**** }}\right)$, whereas for the facultative cultivars, the value of DEV49 measured at 13C showed the strongest correlation with the field data for DEV49 after vernalisation for 30 days $\left(r=0.94^{* * *}\right)$. However, with regard to winter cultivars, DEV49 measured at 23C was correlated most highly with values of DEV49 obtained in the field; similar and strong correlations were evident for 30,45 and 60 days vernalisation $\left(r=0.61^{* * *}, 0.61^{\text {***}}\right.$ and $0.62^{* * *}$, respectively).

\section{Discussion}

The principal goal of the research described herein was to identify the effect of ambient temperature on development in barley by analysing the responses to temperature of a comprehensive set of barley genotypes that were representative of different provenances and germplasm groups. The variety of cultivars and the breadth of responses described herein span the cultivated species in Europe and North America, with smaller representations of other World areas; hence, they encompass a level of diversity that is uncommon in studies of plant and crop physiology.

Under natural conditions the ambient temperature, as an environmental cue, exerts its complex effects on plant development in close association with other environmental factors such as photoperiod, and the quantity and quality of light. The combined effects of these factors also depend strongly on the phenological phase of the plant, when it registers these signals (Pirasteh $\delta$ Welsh, 1980; Borrás-Gelonch et al., 2012; Hemming et al., 2012). This dependence makes it difficult to separate the effects of ambient temperature from those of other factors, and explains the scarcity of information on this phenomenon in cereals (Luo, 2011). We attempted to isolate the effect of ambient temperature by conducting experiments under controlled conditions in which all factors other than temperature were held constant. The plants were subjected to inductive conditions, i.e. a standard vernalisation treatment followed by growth under long days (16 h) under a controlled light spectrum and intensity, to avoid the confounding effects of vernalisation, photoperiod and light quality.

Information on the optimal temperature range for the growth of barley is scarce. However, given the phylogenetic proximity of wheat and barley, it is feasible to use information on wheat as a proxy for barley. For wheat, Porter \& Gawith (1999) identified an optimum ambient temperature range of $17-23^{\circ} \mathrm{C}$ over the course of the entire growing season. This information is complemented by the results of a separate study (Slafer $\mathcal{G}$ Rawson, 1995a), such that the rate of wheat development declined at temperatures higher than $22^{\circ} \mathrm{C}$. In keeping with these findings, the temperatures used in this study were in the suboptimal (13C and 23C) or optimal (16.5C and $18 \mathrm{C}$ ) range. Under such conditions, the ambient temperature also affected barley development, but large differences in responses among genotypes were observed.

Several major types of response to temperature were distinguished under the controlled environmental conditions. These types depended strongly on the seasonal growth habit, with only a small degree of overlap, although the vernalisation requirement of the winter 
barley cultivars was theoretically saturated in the growth chamber experiment (this observation was supported by the results of the field experiment). The largest variation in responses to temperature was shown by the winter cultivars. In general, in the winter cultivars, the range of temperature sensitivity was narrow for temperatures under 18C, because all three clusters required similarly fewer GDD for a given developmental phase at 13C than at 18C. In contrast, striking differences in sensitivity among the winter barley clusters were observed at 23C. Among the spring cultivars, two distinct groups were distinguished that showed again significant difference in sensitivity to temperature towards the warmest temperatures, the level of which was much smaller than in the winter cultivars. The data collected for the different growth habit clusters in the controlled growth chamber tests were in strong agreement with the heading dates recorded under field conditions. The associations between the experiments support the validity of our measurements of sensitivity to temperature. In addition, when we compared the thermal times required to reach heading for barley across the range of ambient temperatures, with those published for four wheat cultivars using a comparable experimental design (Slafer \& Rawson, 1995c), we found good agreement among the basic response types. The only exception was the winter barley cluster Clu4, for which a counterpart in wheat was not identified among the limited number of samples.

Previous studies have developed linear models to characterise crop development in association with ambient temperature between the cardinal temperature points of $T_{\text {base }}$ and $T_{\text {opt }}$ (Slafer $\&$ Rawson, 1995a,b). In this study, these cardinal points could not be established directly because of the limited number of temperature regimes studied. However, results reported in the literature indicate that the $13 \mathrm{C}$ and $18 \mathrm{C}$ regimes apparently lie within the linear section. In this range, linearity was only typical of the winter barley cluster Clu5 throughout all plant developmental phases. However, as plant development advanced, linearity became evident in additional clusters, especially at the DEVSEend developmental phase, in which all clusters showed almost linear associations with ambient temperature, with the remarkable exception of Clu4. Plants subjected to the $23 \mathrm{C}$ treatment showed the largest range of responses, with significant changes in the ranking of the thermal (and chronological) times for the genotypic clusters compared to the other temperature regimes, even though $23 \mathrm{C}$ is close to the optimal temperature that has been established for the most advanced phenophases (Slafer $\delta$ Rawson, 1995b; Atkinson \& Porter, 1996; Porter \& Gawith, 1999).

In Arabidopsis, most genes that participate in temperature-mediated gene regulatory pathways were identified through alterations in the responses of mutant lines when they were grown under $22-23^{\circ} \mathrm{C}$ as compared with $16^{\circ} \mathrm{C}$ (Halliday et al., 2003; Lempe et al., 2005; Lee et al., 2007, 2010). In this set of barley genotypes, two clusters showed particularly unusual responses to 23C: the winter barley cluster Clu4, in which development was extremely accelerated by the $23 \mathrm{C}$ treatment, and the spring barley cluster Clu3, in which development was significantly delayed. The response of Clu4 showed a strong resemblance to that of the thermosensitive late-flowering allele of Eps-Am 1 that was identified in a T. monococcum line (Bullrich et al., 2002). In that genetic background, the higher temperature regime $\left(23^{\circ} \mathrm{C}\right.$ vs $\left.16^{\circ} \mathrm{C}\right)$ significantly inhibited the delaying effect of the late-flowering allele, whereas the regime did not modify the effect of the early flowering allele. Thus, the identification of different responses to the ambient temperature range of 13C to 23C reveals the presence of significant natural variation in responses to ambient temperature in barley. In addition, the identification of barley genotypes with contrasting responses to temperature between and within the different growth habit groups is a possible first step in the determination of genetic components of ambient temperature perception in barley.

We observed that sensitivities to temperature depended on the developmental phase. These observations confirm the findings of Slafer \& Rawson $(1995 b, c)$ in relation to wheat. Comparison of the responses to temperature of the major clusters showed that the differences between the clusters were smaller in magnitude during the early developmental phases and became more pronounced at the later phases, which indicated the general cumulative effects of ambient temperature on plant development. However, significant differences in sensitivity to temperature were detected at the different phenophases. In general, sensitivity to temperature was higher in the early developmental phases DEV31 and DEV30. In other studies, the appearance of the first main stem node was considered to coincide with the stem elongation phase (McMaster, 2005; Borras et al., 2009). However, the results show that the onset of intensive stem elongation can follow, with various time lags, the appearance of the first node. The characteristic response patterns of the barley clusters were caused partially by differences in the duration of precisely this period. At 23C DEV30 proved to be the most sensitive phase for the two clusters (Clu4 and Clu3) that showed the most unique responses to 23C and DEV30 accounted for the largest portion of this specific response. The extreme earliness of Clu 4 at 23C was primarily because the appearance of the first node was followed immediately by the onset of intensive stem elongation without a time lag. In comparison, the lateness of Clu3 reflected the longest 
time lag between DEV31 and the beginning of intensive stem elongation (DEV30).

These results confirm that a variety of factors are involved in the intricate and complex temporal and spatial regulation network of plant development, as was suggested by Boss et al. (2004), and provide an insight into the possible role that ambient temperature may play within this network. The primary environmental cues that determine the vegetative-generative transition are vernalisation and photoperiod (Trevaskis et al., 2007; Distelfeld et al., 2009). However, after the transition has occurred, parallel to the photoperiod, ambient temperature assumes importance as a regulatory cue and acts as the next mechanism for the control of plant development via its regulatory effect on certain phases such as the onset of intensive stem elongation. This mechanism provides the plant with sufficient plasticity to respond to constantly changing environmental factors. If the ambient temperature is suboptimal, onset of stem elongation can be delayed to ensure further protection of the sensitive generative tissues from late spring frosts or low temperature stress. In contrast, under a supraoptimal temperature, the timing of the intensive stem elongation phase is one of the factors responsible for specific responses to temperature.

The genetic mechanisms that are responsible for the ambient temperature-mediated control of the various plant developmental phases are unknown. Several studies have reported substantial variation among cultivars in relation to the duration of the different developmental phases, and genetic studies in bi-parental mapping populations have contributed to the identification of some of the genetic components (Borras et al., 2009; Borras-Gelonch et al., 2010; Borrás-Gelonch et al., 2012; Chen et al., 2009; Reynolds et al., 2009; Chen et al., 2010). However, none of these studies have considered the response to ambient temperature.

The importance of this area of research is underlined by the fact that neither the changes in local conditions that are caused by global climate changes, nor their effects on local adaptation with respect to plant developmental strategies, can be predicted exactly. A more comprehensive and quantitative understanding of the physiological and genetic determinants of the registering of ambient temperature and its effect on time to heading and the partitioning of time among pre-flowering phenophases is a prerequisite to managing the fine-tuning of adaptation, both in the present and future, and to optimising plant development to achieve maximum yield potential. Thus, it is extremely important to characterize the variation that exists in the various phases of plant development in cereal germplasm and to identify those factors that contribute to their genetic control. The present work also demonstrates the importance of studying physiological responses across the range of genetic diversity of any given crop, in this instance specifically among the seasonal growth habit types of barley. The study of the present set of barley cultivars has revealed substantial phenotypic variation in responses to ambient temperature for multiple traits and will contribute to the feasibility of further genetic studies. We speculate that the variety of responses results from the presence of multiple genetic pathways. These systems must be identified in order to breed superior cultivars for regions that are challenged by increasing temperatures under conditions of climate change.

\section{Acknowledgements}

The study was carried out with the financial support of the Hungarian Scientific Research Fund (OTKA NK72913). A. M. C. and E. I. were supported by funding from the Spanish Ministry of Science and Innovation, through projects AGL2010-21929 and HH2008-0013. Some of the cultivars originated from the US CAP project, with the kind help of Professor Patrick M. Hayes. Special thanks to Klara Illés and Viola Tóth for skilful technical assistance in scoring the plant developmental parameters.

\section{References}

Amasino R.M. (2005) Vernalization and flowering time. Current Opinion in Biotechnology, 16, 154-158.

Appendino M.L., Slafer G.A. (2003) Earliness per se and its dependence upon temperature in diploid wheat lines differing in the major gene Eps-Aml alleles. The Journal of Agricultural Science, 141, 149-154.

Atkinson D., Porter J.R. (1996) Temperature, plant development and crop yields. Trends in Plant Science, 1, 119-124.

Balasubramanian S., Sureshkumar S., Lempe J., Weigel D. (2006) Potent induction of Arabidopsis thaliana flowering by elevated growth temperature. PLoS Genetics, 2, el 06.

Bonhomme R. (2000) Bases and limits to using 'degree day' units. European Journal of Agronomy, 13, 1-10.

Borras G., Romagosa I., van Eeuwijk F., Slafer G.A. (2009) Genetic variability in duration of pre-heading phases and relationships with leaf appearance and tillering dynamics in a barley population. Field Crops Research, 113, 95-104.

Borras-Gelonch G., Slafer G.A., Casas A.M., van Eeuwijk F., Romagosa I. (2010) Genetic control of pre-heading phases and other traits related to development in a doublehaploid barley (Hordeum vulgare L.) population. Field Crops Research, 119, 36-47.

Borrás-Gelonch G., Denti M., Thomas W.T.B., Romagosa I. (2012) Genetic control of pre-heading phases in the Steptoe $\times$ Morex barley population under different conditions of photoperiod and temperature. Euphytica, 183, 303-321. 
Boss P.K., Bastow R.M., Mylne J.S., Dean C. (2004) Multiple pathways in the decision to flower: enabling, promoting and resetting. The Plant Cell, 16, S18-S31.

Bullrich L., Appendino M.L., Tranquilli G., Lewis S., Dubcovsky J. (2002) Mapping of a thermo-sensitive earliness per se gene on Triticum monococcum chromosome $1 \mathrm{~A}^{\mathrm{m}}$. Theoretical and Applied Genetics, 105, 585-593.

Casao M.C., Igartua E., Karsai I., Lasa J.M., Gracia M.P., Casas A.M. (2011) Expression analysis of vernalization and day-length response genes in barley (Hordeum vulgare L.) indicates that VRNH2 is a repressor of PPDH2 (HvFT3) under long days. Journal of Experimental Botany, 62, 1939-1949.

Chen Y., Carver B.F., Wang S., Zhang F., Yan L. (2009) Genetic loci associated with stem elongation and winter dormancy release in wheat. Theoretical and Applied Genetics, 118, 881-889.

Chen Y., Carver B.F., Wang S., Cao S., Yan L. (2010 Genetic regulation of developmental phases in winter wheat. Molecular Breeding, 26, 573-582.

Cockram J., Chiapparino E., Taylor S.A., Stamati K., Donini P., Laurie D.A., O'Sullivan D.M. (2007) Haplotype analysis of vernalization loci in European barley germplasm reveals novel $V R N-H 1$ alleles and a predominant winter $V R N$ H1/VRN-H2 multi-locus haplotype. Theoretical and Applied Genetics, 115, 993-1001.

Distelfeld A., Li C., Dubcovsky J. (2009) Regulation of flowering in temperate cereals. Current Opinion in Plant Biology, 12, 178-184.

Farré E.M., Harmer S.L., Harmon F.G., Yanovsky M.J., Kay S.E. (2005) Overlapping and distinct roles of PRR7 and PRR9 in the Arabidopsis circadian clock. Current Biology, 15, $47-54$.

Faure S., Higgins J., Turner A., Laurie D.A. (2007) The FLOWERING LOCUS T-like gene family in barley Hordeum vulgare. Genetics, 176, 599-609.

Franklin K.A. (2009) Light and temperature signal crosstalk in plant development. Current Opinion in Plant Biology, 12, 63-68.

Halliday K.J., Salter M.G., Thingnaes E., Whitelam G.C. (2003) Phytochrome control of flowering is temperature sensitive and correlates with expression of the floral integrator FT. The Plant Journal, 33, 875-885.

Heggie L., Halliday K.J. (2005) The highs and lows of plant life: temperature and light interactions in development. The International Journal of Developmental Biology, 49, 675-687. Hemming M.N., Fieg S., Peacock W.J., Dennis E.S., Trevaskis B. (2009) Regions associated with repression of the barley (Hordeum vulgare) VERNALIZATION1 gene are not required for cold induction. Molecular Genetics and Genomics, 282, 107-117.

Hemming M.N., Walford S.A., Fieg S., Dennis E.S., Trevaskis B. (2012) Identification of high temperature responsive genes in cereals. Plant Physiology (online) DOI: 10.1104/pp.111.192013
Karsai I., Hayes P.M., Kling J., Matus I.A., Mészáros K., Láng L., Bedő Z., Sato K. (2004) Genetic variation in component traits of heading date in Hordeum vulgare subsp. spontaneum accessions characterized in controlled environments. Crop Science, 44, 1622-1632.

Karsai I., Szúcs P., Mészáros K., Filichkina T., Hayes P.M., Skinner J.S., Láng L., Bedô Z. (2005) The Vrn$\mathrm{H} 2$ locus is a major determinant of flowering time in a facultative $\times$ winter growth habit barley (Hordeum vulgare L.) mapping population. Theoretical and Applied Genetics, 110, 1458-1466.

Karsai I., Szúcs P., Kőszegi B., Hayes P.M., Casas A., Bedô Z., Veisz O. (2008) Effects of photo and thermo cycles on flowering time in barley: a genetical phenomics approach. Journal of Experimental Botany, 59, 2707-2715.

Kiss T., Balla K., Veisz O., Karsai I. (2011) Elaboration of a non-destructive methodology for establishing plant developmental patterns in cereals. Acta Agronomica Hungarica, 59, 293-301.

Lee J.H., Yoo S.J., Park S.H., Hwang I., Lee J.S., Ahn J.H. (2007) Role of SVP in the control of flowering time by ambient temperature in Arabidopsis. Genes $\theta$ Development, 21, 397-402.

Lee J.H., Lee J.S., Ahn J.H. (2008) Ambient temperature signaling in plants: an emerging field in the regulation of flowering time. Journal of Plant Biology, 51, 321-326.

Lee J.H., Yoo S.J., Lee J.H., Kim W., Yoo S.K., Fitzgerald H., Carrington J.C., Ahn J.H. (2010) Genetic framework for flowering-time regulation by ambient temperatureresponsive miRNAs in Arabidopsis. Nucleic Acids Research, 38, 3081-3093.

Lempe J., Balasubramanian S., Sureshkumar S., Singh A., Schmid M., Weigel D. (2005) Diversity of flowering responses in wild Arabidopsis thaliana strains. PLoS Genetics, 1, e6.

Lewis S., Faricelli M.E., Appendino M.L., Valarik M., Dubcovsky J. (2008) The chromosome region including the earliness per se locus Eps-Aml affects the duration of early developmental phases and spikelet number in diploid wheat. Journal of Experimental Botany, 59, 3595-3607.

Lobell D.B., Ortiz-Monasterio J.I. (2007) Impacts of day versus night temperature on spring wheat yields: a comparison of empirical and CERES model predictions in three locations. Agronomy Journal, 99, 469-477.

Luo Q. (2011) Temperature thresholds and crop production: a review. Climatic Change, 109, 583-598.

McClung C.R., Davis S.J. (2010) Ambient thermometers in plants: from physiological outputs towards mechanisms of thermal sensing. Current Biology, 20, 1086-1092.

McMaster G.S. (2005) Phytomers, phyllochrons, phenology and temperate cereal development. The Journal of Agricultural Science, 143, 137-150.

Penfield S. (2008) Temperature perception and signal transduction in plants. New Phytologist, 179, 615-628.
1 2 3 4 
Pirasteh B., Welsh J.R. (1980) Effect of temperature on the heading date of wheat cultivars under a lengthening photoperiod. Crop Science, 20, 453-456.

Porter J.R., Gawith M. (1999) Temperatures and the growth and development of wheat: a review. European Journal of Agronomy, 10, 23-36.

Reynolds M., Foulkes M.J., Slafer G.A., Berry P., Parry M.A.J., Snape J.W., Angus W.J. (2009) Raising yield potential in wheat. Journal of Experimental Botany, 60, 1899-1918.

Ruelland E., Zachowski A. (2010) How plants sense temperature. Environmental and Experimental Botany, 69, 225-232.

Salomé P.A., Weigel D., McClung C.R. (2010) The role of the Arabidopsis morning loop components CCA1, LHY, PRR7, and PRR9 in temperature compensation. The Plant Cell, 22, 3650-3661.

Samach A., Wigge P.A. (2005) Ambient temperature perception in plants. Current Opinion in Plant Biology, 8, 483-486.

Slafer G.A., Rawson H.M. (1995a) Base and optimum temperatures vary with genotype and stage of development in wheat. Plant, Cell $\theta$ Environment, 18, 671-679.

Slafer G.A., Rawson H.M. (1995b) Rates and cardinal temperatures for processes of development in wheat: Effects of temperature and thermal amplitude. Australian Journal of Plant Physiology, 22, 913-926.

Slafer G.A., Rawson H.M. (1995c) Intrinsic earliness and basic development rate assessed for their response to temperature in wheat. Euphytica, 83, 175-183.

Strasser B., Alvarez M.J., Califano A., Cerdán P.B. (2009) A complementary role for ELF3 and TFL1 in the regulation of flowering time by ambient temperature. The Plant Journal, 58, 629-640.

Szúcs P., Skinner J.S., Karsai I., Cuesta-Marcos A., Haggard K.G., Corey A.E., Chen T.H.H., Hayes P.M. (2007) Validation of the VRN-H2/VRN-H1 epistatic model in barley reveals that intron length variation in $V R N-H 1$ may account for a continuum of vernalization sensitivity. Molecular Genetics and Genomics, 277, 249-261.

Thines B., Harmon F.G. (2010) Ambient temperature response establishes ELF3 as a required component of the core Arabidopsis circadian clock. Proceedings of the National Academy of Sciences USA, 107, 3257-3262.

Thingnaes E., Torre S., Ernstsen A., Moe R. (2003) Day and night temperature responses in Arabidopsis: Effects on gibberellin and auxin content, cell size, morphology and flowering time. Annals of Botany, 92, 601-612.

Tottman D.R., Makepeace R.J. (1979) An explanation of the decimal code for the growth stages of cereals, with illustrations. Annals of Applied Biology, 93, 221-234.
Trevaskis B., Hemming M.N., Dennis E.S., Peacock W.J. (2007) The molecular basis of vernalization-induced 2 flowering in cereals. Trends in Plant Science, 12, 352-357. 3

Trudgill D., Honek L., Li A.D., van Straalen N.M. (2005) 4 Thermal time - concepts and utility. Annals of Applied 5 Biology, 146, 1-14.

Turner A., Beales J., Faure S., Dunford R.P., Laurie D.A. (2005) The pseudo-response regulator Ppd-H1 provides adaptation to photoperiod in barley. Science, 310, 1031-1034.

Yan L., Fu D., Li C., Blechl A., Tranquilli G., Bonafede M., Sanchez A., Valarik M., Dubcovsky J. (2006) The wheat and barley vernalization gene VRN3 is an orthologue of FT. Proceedings of the National Academy of Sciences USA, 103, $19581-19586$.

Yin X., Kropff M.J., Gourdiaan J. (1996) Differential effects of day and night temperature on development to flowering in rice. Annals of Botany, 77, 203-213.

von Zitzewitz J., Szúcs P., Dubcovsky J., Yan L., Pecchioni N., Francia E., Casas A., Chen T.H.H., Hayes P.M., Skinner J.S. (2005) Molecular and structural characterization of barley vernalization genes. Plant Molecular Biology, 59, 449-467.

\section{Supporting Information}

Additional Supporting Information may be found in the online version of this article:

Figure S1 Establishment of the possible number of clusters within the PCA scatterplot on the basis of the thermal times required to attain the various phenophases under four ambient temperature treatments in 168 barley cultivars $\left(\Delta k_{\mathrm{n}}=\left(\right.\right.$ aveDist $\left._{\mathrm{clu} N}-\operatorname{aveDist}_{(\mathrm{clu} N+1)}\right) /$ aveDist $_{\text {clu } N} ;$ $\left.\operatorname{diff} \Delta k=\Delta k_{N+1}-\Delta k_{N}\right)$.

Table S1 Lists of barley cultivars with information on their origin and allele type in the major plant developmental genes as explained in Materials and Methods

Table S2 Two-way ANOVA without replication of the morphological traits measured in the entire set of barley cultivars

Table S3 Cluster means of the thermal times required to attain nine developmental phases under the four ambient temperature treatments for the six clusters of barley cultivars with different growth habits

Table S4 Group means of the yield component traits under the four ambient temperature treatments for the six clusters of barley cultivars with different growth habits

Table S5 Correlation between the DEV49 values from the field-grown and controlled environment experiments for the 168 barley cultivars

\section{1} 2 3 5 


\section{QUERIES TO BE ANSWERED BY AUTHOR}

IMPORTANT NOTE: Please mark your corrections and answers to these queries directly onto the proof at the relevant place. DO NOT mark your corrections on this query sheet.

Queries from the Copyeditor:

AQ1. LSD values provided as footnote in the table format for Table 1 have been pharsed as footnote text. Please check.

AQ2. Please specify the significance of “***" in the text. 
(WWILY-BLACKWELL

USING e-ANNOTATION TOOLS FOR ELECTRONIC PROOF CORRECTION

Required software to e-Annotate PDFs: Adobe Acrobat Professional or Adobe Reader (version 7.0 or above). (Note that this document uses screenshots from Adobe Reader $\mathbf{X}$ )

The latest version of Acrobat Reader can be downloaded for free at: http://get.adobe.com/uk/readerl

Once you have Acrobat Reader open on your computer, click on the Comment tab at the right of the toolbar:

\begin{tabular}{|c|c|c|c|c|c|c|c|c|c|c|c|c|c|}
\hline 四昌曰 & (1) & 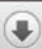 & 1 & $/ 27$ & - & + & $70.4 \%$ & $\checkmark$ & 봉 & $e^{n}$ & $=$ & Tools & Comment \\
\hline
\end{tabular}

This will open up a panel down the right side of the document. The majority of tools you will use for annotating your proof will be in the Annotations section, pictured opposite. We've picked out some of these tools below:

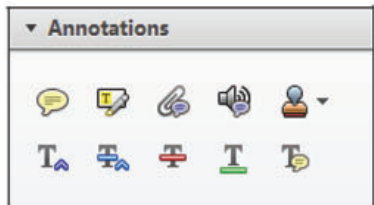

1. Replace (Ins) Tool - for replacing text.

Strikes a line through text and opens up a text box where replacement text can be entered.

How to use it

- Highlight a word or sentence.

- Click on the Replace (Ins) icon in the Annotations section.

- Type the replacement text into the blue box that appears.

Idard tramework for the analysis of $\mathrm{m}$ icy - Nevertheless, it also-led to exogr ole of strateg $\ldots \ldots$ aber of comp 08/06/2011 15:58:17

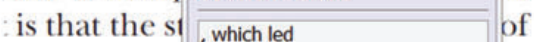
nain compo $\quad$ be level, are exe nc

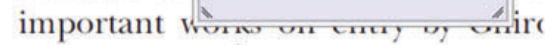
M heneforth' ${ }^{1}$ we nnen the 'hlarl t

3. Add note to text Tool - for highlighting a section to be changed to bold or italic.

T. Highlights text in yellow and opens up a text box where comments can be entered.

How to use it

- Highlight the relevant section of text.

- Click on the Add note to text icon in the Annotations section.

- Type instruction on what should be changed regarding the text into the yellow box that appears.

namic responses of mark ups ent with the VAR evidence

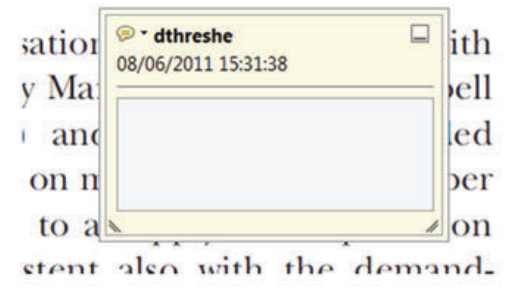

2. Strikethrough (Del) Tool - for deleting text.

Strikes a red line through text that is to be deleted.

How to use it

- Highlight a word or sentence.

- Click on the Strikethrough (Del) icon in the Annotations section.

there is no room for extra prohts al : ups are zero and the number of (et) values are not determined by Blanchard and Kiyotaki (1987), rffect competition in general equilil ts of aggregate demand and supply lassical framework assuming monol sen an everrenoue number of firme

4. Add sticky note Tool - for making notes at specific points in the text.

Marks a point in the proof where a comment needs to be highlighted.

How to use it

- Click on the Add sticky note icon in the Annotations section.

- Click at the point in the proof where the comment should be inserted.

- Type the comment into the yellow box that appears.

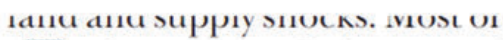

a@imil $\odot$-dthreshe $\quad$. .

numbe 08/06/2011 15:18:08 iff

dard fr.

cy. Ner

le of stu $\square$ w

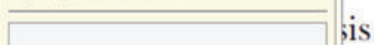

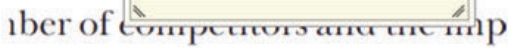
is that the structure of the sects: 


\section{(3)WILEY-BLACKWELL}

\section{USING e-ANNOTATION TOOLS FOR ELECTRONIC PROOF CORRECTION}

5. Attach File Tool - for inserting large amounts of text or replacement figures.

Inserts an icon linking to the attached file in the appropriate pace in the text.

\section{How to use it}

- Click on the Attach File icon in the Annotations section.

- Click on the proof to where you'd like the attached file to be linked.

- Select the file to be attached from your computer or network.

- Select the colour and type of icon that will appear in the proof. Click OK.

E N D

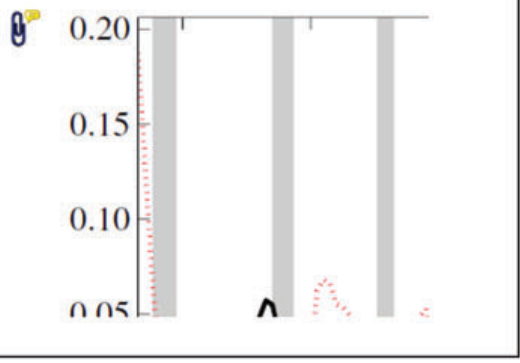

6. Add stamp Tool - for approving a proof if no corrections are required.

3. Inserts a selected stamp onto an appropriate place in the proof.

\section{How to use it}

- Click on the Add stamp icon in the Annotations section.

- Select the stamp you want to use. (The Approved stamp is usually available directly in the menu that appears).

- Click on the proof where you'd like the stamp to appear. (Where a proof is to be approved as it is, this would normally be on the first page).

It the Dusiness cycie, starting with the on perfect competition, constant ret he otaki (1987), has introduced produc general equilibrium models with nomin

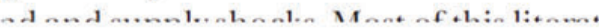

\begin{tabular}{|l|}
\hline Drawing Markups \\
\hline $\mathrm{I}$ 태 $-\Rightarrow \bigcirc \square$ \\
$\square \square \square$ \\
\hline
\end{tabular}

\section{How to use it}

- Click on one of the shapes in the Drawing Markups section.

- Click on the proof at the relevant point and draw the selected shape with the cursor.

- To add a comment to the drawn shape, move the cursor over the shape until an arrowhead appears.

- Double click on the shape and type any text in the red box that appears.
7. Drawing Markups Tools - for drawing shapes, lines and freeform annotations on proofs and commenting on these marks.

Allows shapes, lines and freeform annotations to be drawn on proofs and for comment to be made on these marks.

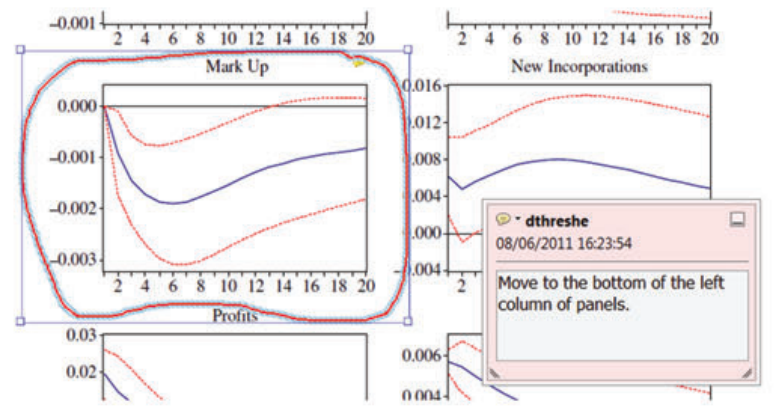

For further information on how to annotate proofs, click on the Help menu to reveal a list of further options:

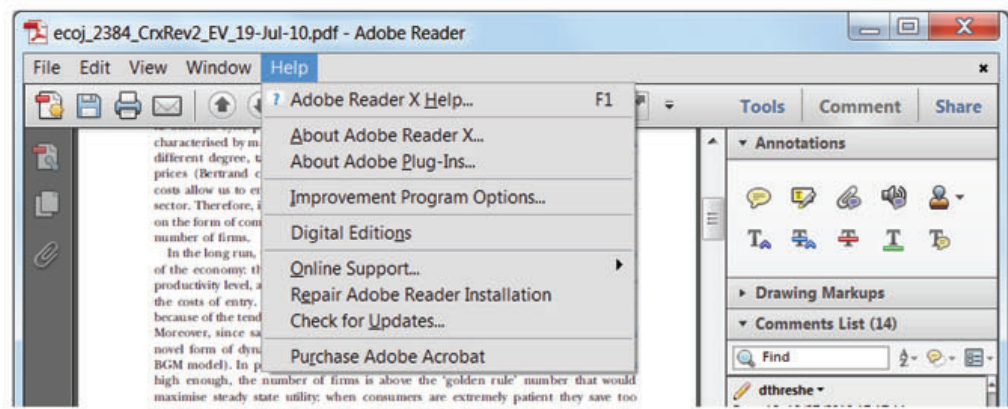

